\title{
Potential for livestock supplementation on smallholder farms in The Gambia
}

\author{
J. C. Tannert, S. J. Holdent, K. Dampha and A. Jallow \\ International Trypanotolerance Centre, PMB 14, Banjul, The Gambia
}

\section{Introduction}

The human population of sub-Saharan Africa is mainly rural and engaged in smallholder agriculture. The population is rapidly expanding and self sufficiency ratios for staple foods falling. Strategies for boosting domestic production include using marginal land for either cultivation or grazing more livestock. Ultimately such practices will accelerate the degradation of sensitive ecosystems which farmers probably would have traditionally avoided. Livestock research must develop technologies which alleviate rural poverty through improved livestock productivity without placing an additional burden on fragile ecosystems.

Savannah woodland is the main source of food for ruminant livestock in semi-arid Gambia. The provision of small quantities of energy- or proteinrich foods can increase livestock productivity in traditionally managed herds and flocks. However, supplementary feeding may only be viable if quality foods are available within the farming community. This study sought to identify potential food resources and farmer knowledge regarding supplementary food use on farms and varying livestock numbers in the Gambia.

\section{Material and methods}

A survey of farm food resources was carried out on 82 smallholder farms in the Gambia. Farmers were interviewed at the end of the dry season, during the wet season and during the harvest period. Farms were selected from 20 villages by stratified randomization based on the socio-economic status of the farm. Farmers were questioned on food and livestock management practices, livestock numbers were counted and hectarage sown to crops measured in order to estimate crop residue dry matter (DM) production.

+ Present address: c/o FCO (Jakarta), King Charles Street, London SW1A 2AH.

\section{Results}

Survey results indicated that farmers had access to a wide range of potential foods which were primarily derived as by-products of crop production and processing for household consumption. Crop residues were the largest on-farm food resource (on DM basis), 30 to $40 \%$ were protein rich groundnut haulms, the rest being cereal stovers. Small quantities of cereal brans (maize, millet, sorghum and rice) were produced on a regular basis. Sesame and groundnut meals were produced annually by a few farms. Farmers also collected and fed leaves and fruit from species of Acacin, Combretum, Ficus, Parkia, Prosopis, Pterocarpus and Terminalia, in addition to a variety of annual legumes, e.g. Alysicarpus spp.

Table 1 Azailability of food resources froin crop residues (dry matter (DM)) on 82 farms of anrying socio-economic status in the Gambia

\begin{tabular}{|c|c|c|c|c|}
\hline & \multicolumn{4}{|c|}{ Socio-economic status } \\
\hline & Rich & Medium & Poor & Significance \\
\hline $\begin{array}{l}\text { Total TLU }{ }^{+} \text {per farm } \\
\text { s.e. } \\
\text { Total crop residue DM } \\
\text { s.e. } \\
\text { Proportion of all farms }\end{array}$ & $\begin{array}{l}48 \cdot 3^{a} \\
12 \cdot 3 \\
26 \cdot 6^{a} \\
5 \cdot 5 \\
0 \cdot 16\end{array}$ & $\begin{array}{c}6 \cdot()^{\mathrm{b}} \\
0.9 \\
11 \cdot 5^{\mathrm{h}} \\
1.1 \\
0.42\end{array}$ & $\begin{array}{l}2 \cdot 0^{r} \\
0 \cdot 6 \\
7 \cdot 3^{r} \\
1 \cdot 1 \\
0.42\end{array}$ & $\begin{array}{l}* \\
*\end{array}$ \\
\hline
\end{tabular}

$a, b, c$ Superscripts indicate significant differences within rows at probability level indicated.

+ Tropical livestock units, where $1 \mathrm{cow} / \mathrm{ox}=0.7 \mathrm{TLU}, 1$ horse $=0.8 \mathrm{TLU}, 1$ donkey $=0.5 \mathrm{TLU}, 1$ small ruminant $=$ 0.1 TLU (FAO Production Yearbook, 1979).

There were large differences in livestock ownership and crop residue availability within the farming community (Table 1). Rich farms produced over 3.5 times the total crop residue DM compared with poor farms. However, poor livestock farmers had the largest crop residue supply per animal at $3.7 \mathrm{t} \mathrm{DM}$ per tropical livestock unit (TLU) compared with rich farms which had only 0.6 DM per TLU. 
Crop residues and by-products were universally fed to draught animals and formed the main component of their diet throughout the year. Quality foods (groundnut hay and cereal brans) were not used as supplements in the strictest sense but formed a large component of draught animal diets as and when they became available. Food surplus to the needs of draught animals was rarely purposefully fed to other livestock. Surplus crop residues were left in the fields and became a common food resource for free ranging cattle. Home food processing by-products (i.e. oilseed meals) were discarded.

\section{Discussion and conclusion}

All farms had a wide variety of foods which could be used as supplementary and/or main dietary components for livestock. Feeding practices for draught animals were well established but farmers rarely applied this knowledge to other livestock. The potential to develop the practice of supplementary feeding was thus high. Crop residues and byproducts could also be optimally allocated to more critical livestock categories.
The potential to improve feeding practices was greatest among poor farmers who had the most favourable food to TLU ratio. Their family welfare, in terms of human nutritional status, was likely to benefit disproportionally more from improved livestock productivity compared with rich, large farms. Poor farmers own a small proportion of total livestock in The Gambia, hence supplementing their animals would have minimal effects on increasing grazing pressure. In contrast, the low ratio of food to TLU on rich farms (who own the majority of cattle) has probably served as a check to national herd expansion. Efforts to improve livestock productivity through better feeding on richer farms may therefore serve to exacerbate an already high stocking rate unless accompanied by measures which promote higher offtake rates.

\section{Acknowledgements}

J. C. Tanner and S. J. Holden were supported by the Overseas Development Administration. The study was financed by the European Development Fund through ILCA and ILRAD. 